\title{
Studi Kelayakan Penuntun Praktikum Asam Basa Berbasis Bahan Lingkungan Menggunakan Model 3-D dan Penerapan Metode Inkuiri Terbimbing untuk Meningkatkan Hasil Belajar Siswa SMA Negeri 1 Tenga
}

\author{
Gerry H. Lumolos ${ }^{* a}$, Dokri Gumolung ${ }^{a}$, Joice Caroles ${ }^{a}$ \\ ${ }^{a}$ Kimia, FMIPA, Universitas Negeri Manado, Minahasa, 95618, Indonesia
}

\begin{tabular}{l} 
I N F O A R T I K E L \\
\hline Diterima 25 Agustus 2019 \\
Disetujui 27 Desember 2019 \\
\\
\hline Key word: \\
Learning Outcomes \\
Acid Bases \\
Guided Inquiry Methods \\
\hline Kata kunci: \\
Hasil Belajar \\
Asam Basa \\
Inkuiri Terbimbing
\end{tabular}

${ }^{*} e$-mail:

gerryh.lumolos@yahoo.com

${ }^{*}$ Telp: 082293618807

\begin{abstract}
A B S T R A C T
Practicum guides are printed teaching materials that students can use in the learning process. This development research aims to determine the feasibility of an acid base practicum guide based on environmental materials with a 3-D model and to improve student learning outcomes through practicum activities and the application of guided inquiry methods. The subject of this research was class XI IPA 1 at SMA Negeri 1 Tenga. The feasibility test for large groups has an average percentage of $88.24 \%$ which means that this practical guide is suitable for use with valid qualifications. Student learning outcomes using post test scores with the technique of statistical analysis of one sample t-test (one sample t-test). The results of the one-sample t-test hypothesis at a level of $\alpha=5 \%$ were obtained tcount $=4.604>$ ttable $=1.708$. The results of this study indicate that guidance practicum based on environmental materials is suitable for use in chemichal subject, and the treatment of practicum giude based on environmental materials with the application of guided inquiry methods can improve learning outcomes of $92.4 \%$ of students on acidic base subject.
\end{abstract}

\section{A BSTRAK}

Penuntun praktikum merupakan bahan ajar dalam bentuk cetak yang dapat digunakan siswa dalam proses belajar pembelajaran. Penelitian pengembangan ini bertujuan untuk mengetahui kelayakan penuntun praktikum asam basa berbasis bahan lingkungan dengan model 3-D dan untuk meningkatkan hasil belajar siswa melalui kegiatan praktikum dan penerapan metode inkuiri terbimbing. Subjek penelitian ini adalah kelas XI IPA 1 di SMA Negeri 1 Tenga. Uji kelayakan kelompok besar terdapat ratarata presentase $88,24 \%$ yang berarti penuntun praktikum ini layak digunakan dengan kualifikasi valid. Hasil belajar siswa menggunakan nilai post test dengan teknik analisis data statistik uji-t satu sampel (one sample t-test). Hasil uji hipotesis uji-t satu sampel pada taraf $\alpha=5 \%$ diperoleh thitung $=4,604>$ tabel $=$ 1,708 . Hasil penelitian ini menunjukan penuntun praktikum asam basa berbasis bahan lingkungan layak digunakan dalam pembelajaran kimia, dan penggunaan penuntun praktikum asam basa berbasis bahan lingkungan dengan penerapan metode inkuiri terbimbing dapat meningkatkan hasil belajar $92.4 \%$ siswa pada materi asam basa.

\section{Pendahuluan}

Ilmu kimia tumbuh dan berkembang melalui eksperimen, sehingga dalam pembelajaran kimia di sekolah perlu dilakukan pendekatan yang berbasis eksperimen khususnya pada materi asam basa. Materi asam basa di kelas XI harusnya disertai dengan kegiatan praktikum berdasarkan standar kurikulum yang ada yaitu pada kegiatan pembelajaran siswa dapat merancang dan 
melakukan percobaan membuat indikator asam basa dari bahan alam dan melaporkannya. Pada kegiatan praktikum siswa dapat lebih memahami tentang teori pelajaran yang mereka terima dari guru melalui eksperimen yqng dilakukan karena mereka akan mengalami sendiri proses ditemukannya suatu teori, dengan dmikian siswa akan lebih yakin atas suatu hal dari pada hanya menerima informasi yang diberikan dari guru dan buku.

Hasil belajar adalah kemampuan kemampuan yang dimiliki siswa setelah dia menerima pengalaman belajarnya. Hasil belajar merupakan tolak ukur keberhasilan siswa dalam belajar. Dari hasil belajar guru dapat menilai apakah proses pembelajaran berhasil atau tidak [1]. Hasil belajar kimia siswa SMA N 1 Tenga khususnya di kelas XI masih sangat bervariasi, terdapat sekitar $45 \%$ siswa dengan hasil belajar diatas KKM dan sekitar 55\% siswa dengan hasil belajar kimia dibawah KKM. Salah satu faktor yang menyebabkan hasil belajar kimia siswa kurang antara lain adalah pembelajaran kimia tidak dilakukan kegiatan praktikum sehingga membuat siswa bosan untuk belajar kimia. Observasi yang dilakukan di SMA Negeri 1 Tenga mengenai praktikum kimia memberi informasi dimana; siswa kelas XI belum pernah melakukan kegiatan praktikum. Menurut salah satu guru kimia sekolah tersebut menyampaikan bahwa kendala tidak dilaksanakan kegiatan praktikum khususnya pada materi asam basa karena jumlah alat dan bahan yang ada dalam laboratorium sudah rusak dan tidak layak digunakan sehingga laboratorium tidak terpakai. Keterbatasan alat dan bahan praktikum sebenarnya bukanlah masalah yang rumit, karena praktikum asam basa bisa terlaksana dengan mengunakan alat dan bahan yang ada di lingkungan tempat tinggal siswa.

Penuntun praktikum berbasis bahan lingkungan dapat menjadi alternatif sebagai usaha untuk membantu guru kimia dalam pelaksanaan praktikum di sekolah. Penuntun praktikum berbasis bahan lingkungan tempat tinggal siswa ini dikembangkan dengan mengaitkan penggunaan bahan-bahan lokal dilingkungan tempat tinggal siswa seperti dari dapur, taman/kebun, apotik, buangan sampah, atau warung/toko/pasar) [2]. Selain itu, penuntun praktikum ini bersifat terbuka, artinya tidak terikat waktu maupun tempat dan dapat diterapkan oleh guru kimia sebagai strategi belajar-mengajar kimia.

Metode pembelajaran merupakan salah satu penunjang dalam pembelajaran. Menurut siswa yang ada disekolah tersebut, metode mengajar yang digunakan oleh guru kimia saat mengajar hanya penggunakan metode ceramah sehingga membuat siswa cenderung malas belajar kimia karena pembelajaran yang terlalu monoton sehingga tidak berdampak besar dalam peningkatan hasil belajar para siswa. Model pembelajaran inkuiri terbimbing efektif membantu guru dalam memotivasi siswa untuk mengajukan pertanyaan yang merupakan bagian penting dari pembelajaran berbasis penyelidikan. Selain itu, dengan model inkuiri terbimbing dapat meningkatkan rasa percaya diri siswa dan dapat meningkatkan prestasi belajar siswa [3]. Tujuan utama dari model inkuiri adalah pengembangan kemampuan berpikir siswa secara ilmiah dalam beraktifitas mencari dan menemukan sesuatu [4]. Metode pembelajaran inkuiri terbimbing dapat meningkatkan adanya rasa keingintahuan siswa terhadap mata pelajaran kimia terlebih pada materi asam basa, sehingga sangat cocok untuk digunakan dalam proses belajarmengajar di SMA.

Penelitian ini merupakan penelitian pengembangan perangkat pembelajaran kimia yanng dikembangkan dengan model pengembangan 4-D yang dimodifikasi menjadi 3-D, yaitu: pendefinisian (define), perencanaan (design), pengembangan (develop). Model pengembangan 3-D ini merupakan salah satu model pengembangan yang dapat digunakan untuk membuat perangkat pembelajaran kimia berbentuk penuntun praktikum. Penuntun praktikum yang akan dirancang menggunakan model 3-D merupakan penuntun praktikum yang memenuhi kriteria valid, praktis, dan efektif serta dapat menumbuhkan minat belajar siswa dalam pembelajaran kimia khususnya pada materi asam basa.

Penelitian ini bertujuan mengetahui kelayakan penuntun praktikum asam basa berbasis bahan lingkungan dengan model pengembangan 3-D. Dan untuk meningkatkan hasil belajar siswa kelas XI di SMA N 1 Tenga 
melalui kegiatan praktikum asam basa menggunakan penuntun praktikum asam basa berbasis bahan lingkungan dngan metode pembelajaran inkuiri terbimbing

\section{Metode}

Model penelitian ini adalah Research and Development $(R \in \mathcal{E} D)$ dengan menggunakan model 3-D. Model pengembangan 3-D meliputi 3 tahap penting yaitu, tahap pendefinisian (difine), tahap perancangan (design), dan tahap pengembangan (develop). Adapun penelitian ini menggunakan pendekatan deskripsi kuantitatif, kuantitatif uji hipotesis.

Teknik analisis data yang digunakan dalam penelitian ini adalah dengann teknik perhitungan menggunakan t-hitung satu sampel (one sample $t$-test) dan teknik perhitungan untuk kelayakan modul menggunakan angket validasi dan dianalisis menggunakan rumus berikut:

Keterangan:

$$
P=\frac{X}{X i} 100 \%
$$

$\mathrm{P}=$ presentase

$\mathrm{x}=$ jawaban responden dalam satu item

$\mathrm{x}_{\mathrm{i}}=$ jumlah skor ideal dalam satu item

\section{Hasil dan Pembahasan}

Kelayakan Penuntun Praktikum

Sesuai dengan model pengembangan penuntun praktikum 3-D, berikut uraian secara lengkap mengenai proses pengembangan penuntun praktikum yang melalui 3 tahap define, design, dan develop.

1. Pendefinisian (define)

a. Analisis ujung depan

Analisis Kebutuhan ini mengacu pada kondisi yang ada di lapangan. Proses pengembangan perangkat pembelajaran dalam penelitian ini diawali dengan mengamati dan mencari informasi mengenai pembelajaran kimia yang ada di kelas XI IPA. Analisis ujung depan (front-end analysis) dilakukan dengan tiga langkah yaitu observasi kegiatan pembelajaran, wawancara dengan guru kimia, dann observasi perangkat pembelajaran yang digunakan. Berdasarkan observasi kegiatan pembelajaran di peroleh informasi bahwa dalam kegiatan belajar mengajar di kelas XI IPA tidak di sertai dengan kegiatan praktikum oleh karena keterbasatan alat dan bahan yang ada di laboratorium sekolah tersebut. Selain itu di peroleh data bahwa masih ada $44 \%$ siswa yang memiliki hasil belajar yang rendah pada mata pelajaran kimis. Salah satu faktor yanng mempengaruhi rendahnya hasil belajar siswa yaitu penggunaan bahan ajar dimana bahan ajar yang digunakan masih berupa buku paket yang tampilannya kurang menarik dan penuntun praktikum yang tidak lengkap prosedur kerja serta alat dan bahan.

b. Analisis siswa (student analysis)

Pada tahap analisis siswa ini, di berikan angket kepada siswa untuk mengetahui bahan ajar dan proses pembelajaran kimia yang mereka inginkan. Angket diberikan kepada 5 siswa yang ada di kelas XI MIA 1. Hasil dari angket, dapat di lihat pada tabel 4.1.

Tabel 1. Hasil angket analisis siswa

\begin{tabular}{|c|c|c|}
\hline No. & Pertanyaan & respon \\
\hline 1 & $\begin{array}{l}\text { Bahan ajar yang sangat } \\
\text { mudah dimengerti }\end{array}$ & $2 \mathrm{SS}, 3 \mathrm{~S}$ \\
\hline 2 & $\begin{array}{l}\text { Bahan ajar yang memiliki } \\
\text { percobaan praktikum }\end{array}$ & SS, $2 S$ \\
\hline 3 & $\begin{array}{lr}\text { Bahan ajar yang memiliki } \\
\text { gambar-gambar yang } \\
\text { mudah dipahami dan } \\
\text { menarik }\end{array}$ & $3 \mathrm{SS}, 2 \mathrm{~S}$ \\
\hline 4 & $\begin{array}{l}\text { Bahan ajar yang memuat } \\
\text { banyak teorinya }\end{array}$ & $\begin{array}{l}1 \mathrm{SS}, 2 \mathrm{~S}, \\
2 \mathrm{TS}\end{array}$ \\
\hline 5 & $\begin{array}{l}\text { Bahan ajar yang memuat } \\
\text { banyak soal-soal latihan }\end{array}$ & $3 \mathrm{~S}, 2 \mathrm{TS}$ \\
\hline 6 & $\begin{array}{l}\text { Sudah memahami apaitu } \\
\text { asam basa }\end{array}$ & $2 \mathrm{SS}, 3 \mathrm{~S}$ \\
\hline 7 & $\begin{array}{l}\text { Dapat menjelaskan teori } \\
\text { asam basa menurut para } \\
\text { ahli }\end{array}$ & $3 \mathrm{SS}, 2 \mathrm{~S}$ \\
\hline 8 & 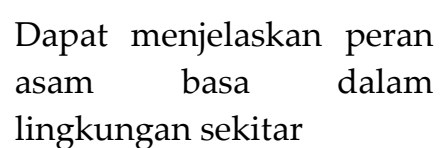 & $3 \mathrm{SS}, 2 \mathrm{~S}$ \\
\hline 9 & $\begin{array}{l}\text { Mampu mengidentifikasi } \\
\text { berbagai jenis indikator } \\
\text { asam basa alami }\end{array}$ & $1 \mathrm{SS}, 4 \mathrm{~S}$ \\
\hline 10 & $\begin{array}{l}\text { Membedakan asam kuat, } \\
\text { asam lemah dan basa kuat, } \\
\text { basa lemah }\end{array}$ & $1 \mathrm{SS}, 4 \mathrm{~S}$ \\
\hline
\end{tabular}

c. Analisis konsep

Pada penelitian yanng dilakukan di SMA 
Negeri 1 Tenga, siswa tertarik pada praktikum berbasis bahan lingkungan, selain itu siswa juga tertarik pada metode pembelajaran inkuiri terbimbing yang dapat mendorong mereka unttuk menemukan konsep kimia sendiri. Analisis konsep yang telah dilakukan pada penelitian ini adalah dengan mengidentifikasi bagian-bagian penting dan utama yang akan dipelajari dan menyusunnya dalam bentuk yang sistematis dan terperinci yang akan masuk pada penuntun praktikum berdasarkan analisis Front-end yaiitu prasyarat, petunjuk penggunaan, Kompetensi Isi (KI), Kompetensi Dasar (KD) dan kriteria keberhasilan pembelajaran kimia. Hal ini didukung oleh hasil wawancara dngan guru mata pelajaran kimia yang menyatakan bahwa belum ada pengembangan penuntun praktikum berbasis bahan lingkungan. Selain itu belum pernah dilakukan penerapan metode inkuiri terbimbing dengan menggunakan penuntun praktikum berbasis bahan lingkungan.

d. Analisis tugas

Tabel 2. Hasil analisis tugas kelas XI pada penuntun praktikum asam basa

\begin{tabular}{|c|c|}
\hline $\begin{array}{c}\text { Kompetensi } \\
\text { dasar }\end{array}$ & $\begin{array}{c}\text { Indikator } \\
\text { pembelajaran }\end{array}$ \\
\hline $\begin{array}{c}\text { Menganalisis } \\
\text { trayek } \\
\text { perubahan pH } \\
\text { beberapa } \\
\text { indikator yang } \\
\text { diekstrak dari } \\
\text { bahan alam } \\
\text { melalui } \\
\text { percobaan }\end{array}$ & 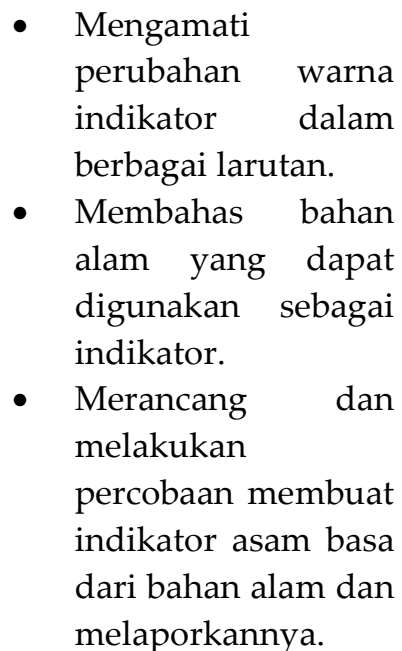 \\
\hline
\end{tabular}

Pada analisis tugas dilakukan analisis kompetensi dasar kemudian menjabarkan indikator pembelajaran. Peneliti menganalisis tugas-tugas pokok yang harus dikuasai siswa agar siswa dapat mencapai ketentuan kompetensi minimal. Berdasarkan hasil analisis diperoleh gambaran mengenai tugas-tugas yang diperlukan dalam proses pembelajaran yang sesuai dengan kompetensi dasar. Berikut ini merupakan hasil analisis tugas yang diambil dari kompetensi dasar dan indikator serta tujuan pembelajaran yang ada pada materi asam basa

e. Perumusan tujuan pembelajaran

Berdasarkan analisis-analisis yang telah dilakukan, ini diperoleh tujuan-tujuan pembelajaran yang akan dicapai pada modul yang dikembangkan sebagai berikut:

Tabel 3. analisis tujuan pembelajaran

\begin{tabular}{|c|c|}
\hline $\begin{array}{c}\text { Indikator } \\
\text { Pembelajaran }\end{array}$ & $\begin{array}{c}\text { Tujuan } \\
\text { Pembelajaran }\end{array}$ \\
\hline $\begin{array}{c}\text { - Mengamati } \\
\text { perubahan warna } \\
\text { indikator dalam } \\
\text { berbagai larutan. } \\
\text { - Membahas bahan } \\
\text { alam yang dapat } \\
\text { digunakan } \\
\text { sebagai indikator. } \\
\text { - Merancang dan } \\
\text { melakukan } \\
\text { percobaan } \\
\text { membuat } \\
\text { indikator asam } \\
\text { basa dari bahan } \\
\text { alam dan } \\
\text { melaporkannya. }\end{array}$ & 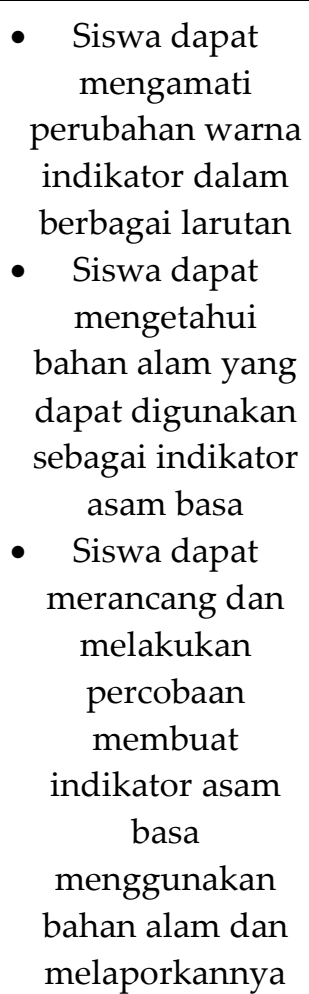 \\
\hline
\end{tabular}

2. Perancangan (design)

a. Penyusunan pedoman praktikum

Tahap penyusunan pedoman praktikum ini adalah langkah awal untuk menggabungan tahap define dan tahap design. Penuntun praktikum disusun berdasarkan hasil perumusan dari kompetensi dasar, indikator, dan tujuan pembelajaran serta analisis siswa. Peneliti memilih untuk membuat penuntun praktikum pda materi asam basa karena sesuai 
dngan tanggapan siswa yang sangat tertarik untuk melakukan praktikum menggunakan bahan lingkungan karena pada praktikum asam basa dapat memanfaatkan alat dan bahan lingkungan yang tentunya lebih murah dan mudah untuk didapat. Penuntun praktikum inilah yang nantinya digunakan untuk membantu meninggatkan hasil belajar siswa pada materi asam basa.

b. Pemilihan alat dan bahan

Pemilihan alat dan bahan untuk praktikum asam basa ini peneliti memilih alat dann bahan dari lingkungan tempat tinggal siswa agar lebih murah dan lebih mudah untuk didapatkan.

Tabel 4. Alat dan bahan

\begin{tabular}{llll}
\hline \multicolumn{2}{c}{ Alat } & \multicolumn{2}{c}{ Bahan } \\
\hline - Lumpang dan & $\bullet$ & Kunyit \\
- alu Gelas plastik & $\bullet$ & Kulit buah manggis \\
- Sendok & $\bullet$ & Bunga kembang \\
- Tabung reaksi & & sepatu \\
- Rak tabung & - Bungah belimbing \\
- reaksi Pipet tetes & - Akuluh \\
- Wadah kaca & - Alkohol 95\% \\
- Saringan & - Air jeruk nipis \\
& & $\bullet$ & Cuka \\
\hline
\end{tabular}

c. Pemilihan metode pembelajaran

Pemilihan metode pembelajaran pada penelitian ini berdasarkan hasil observasi yang telah dilakukan pada tahap analisis ujung depan dan analisis siswa yaitu siswa cenderung lebih tertarik pada model pembelajaran yang dapat mendorong mereka menemukan konsep kimia dari permasalahan yang ada. Pada penelitian ini metode pembelajaran inkuiri terbimbing dilakukan sebagai metode pembelajaran yang akan diterapkan dikelas.

d. Pemilihan format penuntun praktikum

Adapun format yang digunakan dalam penelitian ini adalah:

- Halaman depan (cover)

Berisikan judul praktikum dan ilustrasi gambar yang disesuaikan dengan percobaan asam basa berbasis bahan lingkungan yang akan dilakukan.

- Kata pengantar
Berisikan ucapan dari penulis atas selesainya penuntun praktikum baik tentang ucapan rasa syukur, ucapan terima kasih maupun tujuan dan manfaat dari penuntun praktikum.

- Tata-tertib laboratorium

Berisikan tentang apa yang harus dilakukan siswa didalam laboratorium dan apa yang tidak boleh dilakukan siswa saat berada di laboratorium.

- Daftar isi

Daftar isi berisikan petunjuk halaman penuntun praktikum agar mempermudah siswa dalam menggunakannya.

- Materi praktikum

Berisikan materi praktikum yaitu asam basa.

- Percobaan praktikum

Mencakup: tujuan percobaan, alat daan bahan, prosedur kerja, tabel hasil pengamatan, analisa data, dan pertanyaan.

- Lembar kerja siswa (LKS)

- Daftar pustaka.

3. Pengembangan (development)

a. Validasi tim ahli

Hasil yang diperoleh dari validasi tim ahli adalah sebagai berikut:

Tabel 5. Hasil validasi tim ahli

\begin{tabular}{ccc}
\hline No. & Validator & Hasil (\%) \\
\hline 1 & Ahli media & $83,3 \%$ \\
2 & Ahli bahasa & $84,2 \%$ \\
3 & Ahli materi & $84 \%$ \\
\hline
\end{tabular}

b. Uji coba kelompok kecil

Uji coba kelompok kecil mendapatkan hasil seperti yang tercantum dalam tabel 6 .

Berdasarkan hasil respon siswa pada uji kelompok kecil maka didapatkan nilai rata-rata hasil uji kelompok kecil yaitu 88,77\%, maka skor yang didapatkan termasuk dalam kualifikasi valid.

Tabel 6. Hasil uji coba kelompok kecil 
c. Uji coba kelompok besar

\begin{tabular}{|c|c|c|c|c|c|}
\hline \multirow[t]{2}{*}{ No } & \multirow[t]{2}{*}{ Nama } & \multicolumn{3}{|c|}{ Aspek Penilaian } & \multirow{2}{*}{$\begin{array}{c}\text { Presen } \\
\text { tase } \\
(\%)\end{array}$} \\
\hline & & $\begin{array}{l}\text { Tam- } \\
\text { pilan }\end{array}$ & $\begin{array}{c}\text { Mate- } \\
\text { ri }\end{array}$ & $\begin{array}{r}\text { Man- } \\
\text { faat }\end{array}$ & \\
\hline 1 & E.P & 30 & 36 & 20 & $85,4 \%$ \\
\hline 2 & V.W & 33 & 37 & 22 & $91,9 \%$ \\
\hline 3 & M.M & 32 & 35 & 21 & $87,9 \%$ \\
\hline 4 & K.M & 33 & 35 & 19 & $86 \%$ \\
\hline 5 & K.N.M & 33 & 34 & 21 & $88 \%$ \\
\hline 6 & J.L & 31 & 37 & 22 & $90,6 \%$ \\
\hline 7 & M.M & 33 & 35 & 21 & $88,8 \%$ \\
\hline 8 & E.T & 33 & 35 & 22 & $90,2 \%$ \\
\hline 9 & L.L & 34 & 32 & 23 & $89,9 \%$ \\
\hline 10 & L.S & 32 & 33 & 23 & $89 \%$ \\
\hline
\end{tabular}

Uji coba kelompok kecil mendapatkan hasil sebagai berikut:

Tabel 7. Hasil uji kelompok besar

\begin{tabular}{|c|c|c|c|c|c|}
\hline \multirow{2}{*}{ No } & \multirow{2}{*}{ Nama } & \multicolumn{3}{|c|}{ Aspek penilaian } & \multirow{2}{*}{$\begin{array}{c}\text { Presen } \\
\text { tase } \\
(\%)\end{array}$} \\
\hline & & $\begin{array}{l}\text { Tam- } \\
\text { pilan }\end{array}$ & $\begin{array}{l}\text { Ma- } \\
\text { teri }\end{array}$ & $\begin{array}{c}\text { Man- } \\
\text { faat }\end{array}$ & \\
\hline 1 & M.R & 32 & 37 & 20 & $88.2 \%$ \\
\hline 2 & B.J & 31 & 36 & 22 & $89.3 \%$ \\
\hline 3 & G.T & 30 & 37 & 21 & $87.7 \%$ \\
\hline 4 & T.K & 32 & 33 & 23 & $89 \%$ \\
\hline 5 & A.R & 35 & 36 & 23 & $94.6 \%$ \\
\hline 6 & K.R & 32 & 36 & 23 & $87.2 \%$ \\
\hline 7 & E.E & 32 & 34 & 23 & $92.4 \%$ \\
\hline 8 & J.M & 31 & 30 & 21 & $82.8 \%$ \\
\hline 9 & F.T & 33 & 32 & 22 & $87,7 \%$ \\
\hline 10 & A.M & 32 & 35 & 22 & $89,3 \%$ \\
\hline 11 & S.K & 32 & 34 & 22 & $88,4 \%$ \\
\hline 12 & J.M & 32 & 33 & 21 & $86,2 \%$ \\
\hline 13 & S.S & 30 & 33 & 22 & $85,8 \%$ \\
\hline 14 & Y.K & 34 & 34 & 20 & $87,4 \%$ \\
\hline 15 & E.L.E & 32 & 38 & 19 & $87,6 \%$ \\
\hline 16 & A.H & 30 & 35 & 21 & $86,1 \%$ \\
\hline 17 & G.S & 32 & 33 & 20 & $86,3 \%$ \\
\hline 18 & S.M & 33 & 34 & 17 & $82.6 \%$ \\
\hline 19 & N.M & 28 & 35 & 23 & $87 \%$ \\
\hline 20 & A.T & 33 & 37 & 22 & $91,9 \%$ \\
\hline 21 & A.L & 32 & 38 & 22 & $91,8 \%$ \\
\hline 22 & R.P & 29 & 33 & 21 & $83,5 \%$ \\
\hline 23 & S.P & 32 & 36 & 20 & $88 \%$ \\
\hline 24 & F.S & 33 & 35 & 22 & $90,2 \%$ \\
\hline
\end{tabular}

\begin{tabular}{llllll}
25 & B.T & 33 & 38 & 22 & $92,7 \%$ \\
26 & J.K & 34 & 38 & 20 & $90,7 \%$ \\
\hline
\end{tabular}

Berdasarkan hasil respon siswa pada uji kelompok besar maka didapatkan nilai rata-rata hasil uji kelompok besar yaitu 88,24\%, maka skor yang didapatkan termasuk dalam kualifikasi valid.

\section{Hasil Belajar}

Berdasarkan nilai post test dari 26 siswa dikelas X IPA I maka, dapat dilakukan perhitungan uji-t satu sampel sebagai uji hipotesis.

Hasil pengujian hipotesis dapat dilihat pada tabel 8 .

Tabel 8. Ringkasa hasil pengujian hipotesis kelas XI IPA 1

\begin{tabular}{cccccc}
\hline $\begin{array}{c}\text { Jum- } \\
\text { lah } \\
\text { respon } \\
\text { den }\end{array}$ & $\begin{array}{c}\text { Mea } \\
\mathbf{n}\end{array}$ & $\begin{array}{c}\text { Stan- } \\
\text { dar } \\
\text { devi- } \\
\text { asi }\end{array}$ & Thitung & Ttabel & $\begin{array}{c}\text { Kesim- } \\
\text { pulan }\end{array}$ \\
\hline $\mathbf{2 6}$ & 85,11 & 11,201 & 4,604 & 1,70 & $\begin{array}{c}\text { Tolak } \\
\text { Ho } \\
\end{array}$ \\
538 & 1 & & 8 & $\begin{array}{c}\text { Ho } \\
\text { thitung }> \\
\text { ttabel })\end{array}$ \\
\hline
\end{tabular}

Pembahasan

Pada uji validasi tim ahli menggunakan instrumen berupa angket untuk menilai kelayakan penuntun praktikum dari tiga aspek yaitu, media, bahasa, dan materi. Berdasarkan penilaian ahli media diperoleh hasil presentase $75 \%$ sehingga dapat disimpulkan bahwa produk penuntun praktikum yang di kembangkan cukup layak sehingga perlu di revisi kembali sesuai dengan saran-saran yang diberikan oleh ahli media. Saran dan masukan yang perlu diperbaiki dari ahli media yaitu gambar-gambar pada cover penuntun praktikum harus sesuai dengan bahan-bahan yang digunakan dalam kegiatan praktikum, mengurangi kontras warna, dan perbaiki kesalahan pada penulisan. Kemudian produk diperbaiki sesuai dengan saran dan masukan yang diberikan oleh ahli media. Setelah melakukan revisi produk, kemudian dilakukan kembali penilaian kelayakan modul tahap 2 pada ahli media dengan hasil yang diperoleh yaitu $83,3 \%$ yang menunjukan bahwa produk 
penuntun yang dihasilkan memiliki kualifikasi layak dan dapat digunakan dalam pembelajaran kimia pada materi asam dan basa. Penilaian ahli bahasa diperoleh hasil $84,4 \%$, jika dicocokan dengan tabel kriteria maka skor yang didapat menujukan kualifikasi layak dan produk penuntun praktikum dapat digunakan dalam kegiatan belajar kimia pada materi asam dan basa sesuai dengan saran-saran yang diberikan yaitu, memperbaiki kesalahankesalahan penulisan yang ada pada penuntun praktikum. Penilaian ahli materi diperoleh hasil $84 \%$, jika dicocokan dengan tabel kriteria maka skor yang didapat menunjukan kualifikasi layak sehingga produk yang dihasilkan dapat digunakan pada kegiatan belajar kimia pada materi asam basa dengan mengikuti saran dan masukan yang diberikan.

Setelah melakukan validasi uji tim ahli, produk penuntun praktikum yang dihasilkan kemudian di lakukan uji coba pada kelompok kecil dan uji kelompok besar menggunakan instrumen angket respon siswa. Berdasarkan uji kelompok kecil yang dilakukan teridiri dari 10 orang siswa kelas XI IPA 2 dengan hasil yang di peroleh masing-masing presentase secara berurutan $85,4 \%, 91,9 \%, 87,9 \%, 86 \%, 88 \%$, $90,6 \%, 88 \%, 90,2 \%, 89,9 \%$, dan $89 \%$ maka dari hasil tersebut mendapatkan presentase kelayakan rata-rata dari uji kelompok kecil adalah $88,77 \%$. Skor yang di peroleh pada uji kelompok kecil berada pada presentase $81 \%$ $100 \%$ dengan kriteria sangat baik, maka dari itu penuntun praktikum tersebut dapat dinyatakan valid dan layak untuk diujicobakan pada kelompok besar.

Pada pengujian kelompok besar terdiri dari 26 siswa kelas XI MIA 1 menggunakan instrumen penelitian berupa angket respon siswa terhadap penuntun praktikum dengan masing-masing hasil presentase secara berurutan $88,2 \%, 89,3 \%, 87,7 \%$, 98\%, 94,6\%, $87,2 \%, 92,4 \%, 92,8 \%, 87,7 \%, 89,3 \%, 88,4 \% 86,2 \%$, $85,8 \%, 87,4 \%, 87,6 \%, 86,1 \%$, 86,3\%, 82,6\%, 87\%, $91,9 \%, 91,8 \%$, 83,5\%, 88\%, 90,2\%, 92,7\%, dan $90,7 \%$ maka dari masing-masing hasil presentase tersebut, didapatkan rata-rata presentasekelayakan dari uji coba kelompok besar yaitu $88,24 \%$. Hasil uji coba kelompok besar tersebut, penuntun praktikum yang dibuat berada pada presentase kelayakan $81 \%$ -
$100 \%$ yang berarti produk penuntun praktikum tersebut dinyatakan valid dan layak.

Berdasarkan data hasil dari post test, ratarata hasil belajar siswa pada materi asam basa setelah menggunakan penuntun praktikum dan penerapan metode inkuiri terbimbing adalah 85,11 yang berarti lebih tinggi dari nilai KKM (75), dengan hasil pengujian hipotesis menggunakan uji statistik uji-t satu sampel (one sample t-test) pada taraf $\alpha=5 \%$ dengan hasil yang diperoleh thitung $=5,604>$ tabel $=1,708\left(\mathrm{H}_{0}\right.$ ditolak).

Dari data uji hipotesis yang telah diperoleh dalam penelitian ini menunjukan bahwa terdapat peningkatan hasil belajar kimia siswa kelas XI IPA 1 pada materi asam basa setelah penggunaan penuntun praktikum dalam kegiatan praktikum dengan penerapan metode mengajar inkuiri terbimbing. Hal ini dikarenakan dalam proses pembelajaran siswa tidak hanya menjadi pendengar tetapi siswa dapat mencari informasi sendiri dan memecahkan masalah melalui kegiatan ilmiah dalam hal ini adalah kegiatan praktikum.

\section{Kesimpulan}

Berdasarkan nilai dari tim ahli yaitu, $83,3 \%, 84,2 \%$, dan $84 \%$ serta nilai hasil respon siswa yaitu, $88,24 \%$, penuntun praktikum berada pada interval $81 \%-100 \%$ dengan kualifikasi valid, mqka dapat di simpulkam bahwa penuntun praktikum asam basa berbasis bahan lingkungan dengan model 3-D layak digunakan dalam proses pembelajaran kimia dikelas. Rata-rata hasil belajar siswa pada materi asam basa dengan menggunakan penuntun praktikum asam basa berbasis bahan lingkungan dengan penerapan metode inkuiri terbimbing adalah 85,11 yang menunjukan lebih tinggi dari nilai KKM sekolah yqng ditentukan yaitu 75 , dan masih terdapat $7.6 \%$ siswa yg memiliki hasil belajar dibawah nilai KKM.

\section{Daftar Pustaka}

1. Sudjana, N., Metode statistika. Bandung: Tarsito 2005, 168.

2. HAM, M. M., Pengembangan dan implementasi model praktikum kimia 
berbasis lingkungan tempat tinggal siswa pada SMU di Bandung. Jurnal Pengajaran MIPA 2005, 6, (1), 61-73.

3. Setiowati, H.; Saputro, A. N. C.; Setyowati, W. A. E., Penerapan Model Pembelajaran Inkuiri Terbimbing (Guided Inquiry) Dilengkapi LKS Untuk Meningkatkan Aktivitas Dan Prestasi Belajar Siswa Pada Materi Pokok Kelarutan Dan Hasil Kali Kelarutan Kelas XI MIA SMA Negeri 1 Banyudono Tahun Pelajaran 2014/2015. Jurnal Pendidikan Kimia 2015, 4, (4), 54-60.

4. Waluyo, M. E.; Parmin, P., Pengembangan panduan praktikum IPA terpadu berbasis inkuiri terbimbing tema fotosintesis untuk menumbuhkan keterampilan kerja ilmiah siswa SMP. Unnes Science Education Journal 2014, 3, (3). 